\title{
The Irrational Thoughts among Najran University Students and Its Relation with Some Variables
}

\author{
Najeh Mohamed Zawahreh \\ Faculty of Education, Najran University, K.S.A \\ E-mail: najeh1968@yahoo.com \\ Ahmed Mohammed Bani Ismail \\ Faculty of Education, Najran University, K.S.A \\ E-mail: ahmad75aa@yahoo.com
}

Received: May 9, 2016 Accepted: August 16, 2016 Published: August 16, 2016

doi:10.5296/jse.v6i3.9434 URL: http://dx.doi.org/10.5296/jse.v6i3.9434

\begin{abstract}
The current study aimed to identify the irrational thoughts among Najran University students and its relationship with some variables [gender, academic level, type of college "humanities, scientific"].To achieve the objectives of the study, Albert Ellis' Irrational Beliefs Scale was utilized, which was modified and developed by Alrihani (1987) to keep up with the Arab environment. The sample consisted of (293) male and female students from various colleges of Najran University, who randomly chosen. The results showed that the irrational thoughts spread moderately, and the study indicated that there are statistical differences in the degree of spread due to gender in favor of males; the study also revealed that there are statistical differences in the degree of spread due to college type in favor of colleges of humanities. It also showed that there are statistical differences in the degree of spread due to the academic level in favor of the first and second levels.
\end{abstract}

Keywords: Irrational Thoughts, University Students 


\section{Introduction}

One of the goals of education is the care of mental health and to liberate individuals from irrational thinking, which is in consistence with the main goal of education in our educational system that is to mentally, psychologically, physically, socially, and emotionally reinforce the student's normal growth to be a good citizen to serve himself and his community. The educational psychologists confirm that the goal is not only to give information to the student but the keenness on student growth and the integration of his personality in various aspects; and the goal of education is to increase mental awareness and encourage logical thinking. It is worth mentioning that mental health plays an important role in education, where it has become the closes behavioral science to the life of the individual in confronting the problems of psychological, emotional, social and educational compatibility (Alshenawi, 1994)

Knowledge scientists confirm that cognitive disorder and distortion of thinking about the self and the future cause the emergence of irrational thoughts and the continuation of neurotic symptoms, where the individual aggrandizes the negative aspects of something and degrades the positive ones, circulates failure, predicts disasters and self-blaming and standard exaggeration; all this is linked to cognitive formation of the individual and how they perceive and explain events (Corey, 2013). Ellis found that the behaviors of his patients are not the result of learning and conditioning, but was the result of social and biological preparations to keep the thoughts and trends illogical (Al-ezza \& Ezzat, 1999)

After Albert Ellis had developed his theory (mental-emotional therapy), research and studies on irrational thoughts increased; although his theory depended on personality, it is also a way of counseling and psychotherapy. This theory based on the human events that are caused by out-of-human will factors, but man has the ability to take actions that will organize and adjust his behavior and his future life (Al-Zyoud, 2008)

Ellis assures that the irrational thinking takes the form of cognitive disorder, or distorted unreal perception for the self and negative events experienced by the individual, and the tendency for rationality clearly appears in adulthood and perhaps after that phase; this requires a lot of effort from the part of the individual who has irrational thoughts, and may need treatment. (Maddi, 1996)

Murray (1999) emphasizes that there is a direct correlation between irrational thoughts and self-frustrating emotions represented in depression, anxiety and aggression. Abu Sha'ar (2007) sees that the difficult economic conditions may directly and indirectly contribute to the spread of irrational thoughts, where neediness and poverty are all factors that lead to a lack of proper mindset and affect the purity of sound mental perceptions that make the individual adopt various forms of irrational thinking. The significance of studying the irrational thoughts emerges from many of the problems that directly affect the lives of the individual, the academic problems are the most prominent (test anxiety), and problems related to self-alienation. Abdel-Ghaffar (2007) conveys that the irrational thoughts have a negative impact on the self-perceived efficiency, where the availability of these thoughts makes the self-defeating thoughts have a wide presence in the mind of the individual. 
Stanciu (2014) reveals that the irrational thoughts are largely associated with symptoms of anxiety and depression, he also pointed out that the irrational thoughts largely spread in the years that precede adulthood, the study showed that younger students and those who are in high school are more affected by the irrational thoughts than university students.

Abdel-Ghaffar conducted a study(2007) to determine the irrational thoughts among a sample of university students; the study showed statistically significant differences between males and females in the rates of spreading irrational thoughts. The study also indicated that there are significant differences between these irrational thoughts attributed to academic major. Hassan and Al-Jammal (2003) aimed to identify the prevalence rate of irrational thoughts among the students of the Faculty of Education. The results indicated that the spread of irrational thoughts among students ranged between(10.29\%)and(48.5\%), the study pointed that there is no impact of gender in the spread of irrational thoughts.

Asaleya (2002) aimed at identifying the irrational thoughts among university students as well as to identify the impact of each of the variables of gender and cultural level. The study resulted that the effectiveness of emotional mental-behavioral therapy is great for modifying the irrational thoughts, which reduced anxiety levels among students. Mejali (2011) sought to identify the extent of the spread of the irrational thoughts among students of the Faculty of Education in Amran University in Yemen. The results of the study indicated that there are statistically significant differences in the degree of spread due to the variable of gender.

Khaledian, Saghafi, Moradi \& Khairkhah (2013) conducted a study, in Iran, aimed to indicate the relationship between irrational thoughts and anxiety among two samples of university students. The study indicated a statistically significant positive relationship between irrational thoughts on the one hand and between the high rate of anxiety among university students on the other hand, and the females were more anxious than males because of their rising irrational thoughts, and it was the students of the first years in both universities are the most anxious because of the quality of irrational thoughts they have. Smith conducted a study (2008) in Spain aimed to reveal the relationship between the irrational thoughts and tension among a sample of university students, and the results showed statistically significant differences in the level of irrational thoughts in favor of females in the domains of catastrophic scenarios and exaggeration in the performance of tasks. The results showed also a direct statistically significant relationship between the rise of irrational thoughts and increase of tension among university student, especially in the first two years compared to the third and fourth year.

There is also a study conducted by Mundada (2013) in India, which aimed to disclose the relationship between the irrational thoughts and locus of control among undergraduate Indian students, the results of the study showed a low level of superstitious thinking among students with internal locus of control, but the students with external locus of control and students from the countryside were of high level on the scale of irrational beliefs, and the results showed also that the level of irrational beliefs among females was higher than males.

Sachs conducted a study (2004) in China that aimed to investigate the relationship between irrational thoughts and self-efficacy among a sample of Chinese post-graduate students. The 


\section{Macrothink}

Journal of Studies in Education

ISSN 2162-6952

2016, Vol. 6, No. 3

study pointed to the existence of inverse relationship between the superstitious thinking and self-perceived competence, and the results showed that there were no statistically significant differences in the level of the spread of irrational thoughts that was moderate between males and females.

\section{Significance}

This study is significant as it tries to shed light on the extent of the spread of the irrational thoughts among students of Najran University, where the students are mostly descended from various tribes with significant and influential role represented in the values, customs and traditions that cover and control the students' behaviors, so the researcher believes that the cultural and structural composition of the tribal community may have a negative impact on the spread of irrational thoughts.

Statement of the problem

The problem of the study seeks to answer the following questions:

1. What is the degree of the spread of the irrational thoughts among Najran University students?

2. Are there any statistically significant differences in the prevalence of the irrational thoughts among students due to gender?

3. Are there any statistically significant differences in the degree of the spread of irrational thoughts among students due to the type of college (scientific, humanities)?

4. Are there any statistically significant differences in the degree of spread of irrational thoughts among students due to the academic level?

\section{Methodology}

\subsection{The study population}

Najran University students (males and females) form the study population.

\subsection{Sampling}

The sample consisted of (293) students randomly selected from two colleges: humanities college and scientific one.

\subsection{Instrument}

To achieve the objectives of the study, Albert Ellis' Irrational Beliefs Scale was utilized, which has been developed to suit the Arab environment by Alrihani (1987).

\subsubsection{Validity}

The scale has been reviewed and evaluated by (14) referees from faculty members at the University of Najran and were asked to edit the paragraphs of the instrument to commensurate with the Saudi environment. The scale applied to a pilot sample and 
correlation coefficients of the paragraphs were calculated and ranged between (34.0) and (69.0) that were statistically significant.

\subsubsection{Reliability}

The researchers checked and calculated the reliability using the methods of retest and Cronbach's alpha (internal consistency). Re-testing: the researchers applied the scale of the irrational thoughts to a sample of (60) students outside the study sample; and a re-test conducted two weeks later on the same sample, correlation coefficients calculated and the total reliability coefficient of the scale was (89.0). Cronbach alpha coefficient (internal consistency) was calculated (83.0)and this is a good and appropriate indicator that the scale has a great deal of reliability to achieve the objectives of this study.

\section{Results \& Discussion}

Results related to the first question: What is the degree of the spread of the irrational thoughts among Najran University students? To answer the first question, the researcher's calculated means, standard deviations for one sample as shown in table (1).

Table 1. The means and standard deviations in the degree of spread of the irrational thoughts

\begin{tabular}{l|c|c|c|c|c|c|c}
\hline & $\mathrm{N}$. & Mean & $\begin{array}{c}\text { Std. } \\
\text { Deviation }\end{array}$ & $\begin{array}{c}\text { Std. Error } \\
\text { Mean }\end{array}$ & $\begin{array}{c}\text { Mean } \\
\text { Difference }\end{array}$ & $\begin{array}{c}\text { Degree of } \\
\text { freedom }\end{array}$ & $\begin{array}{c}\text { Sig. } \\
\text { (2-tailed) }\end{array}$ \\
\hline Irrational & 293 & 67.8635 & 5.10725 & .29837 & - & 292 & .000 \\
thoughts & & & & & $10.13652-$ & & \\
\hline
\end{tabular}

Table (1) indicates that the number of participants (students) was (293) and the mean scores on the scale (67.86) with a standard deviation $=(5.11)$ and T-value $=(78)$ with mean difference $=(10: 13)$.

To make sure of the significance of this difference, the researchers applied t-test to one sample, where degree of freedom $=(292)$ and total P-value $=(000)$ and this value is considered smaller than P-value (0.05) of the study, therefore, the null hypothesis is rejected. The results showed that the spread of irrational thoughts among Najran University students was moderate. This result is consistent with the results of Stanciu (2014), Sachs (2004), Hassan and Al-Jammal(2003) and the study of Abu Sha'ar (2007).

The researchers believe that the low level of adopting irrational thoughts among students is attributed to the good level of economic welfare in which they live, which enabled them to possess tools and means of opening up to several cultures, in addition to the possession of the means of modern technology of the Internet and latest computers and cell phones. The good economic conditions also helped them to a great extent travel outside their home countries, which has helped to bridge the gap between their own culture and the world cultures, which helped increase the opportunities for interaction and common understanding of many things and issues related to human life. The psychological pressures facing the individual are avoided by good economic situations, which will be positively reflected on his lifestyle and his way of thinking. 
Results related to the second question: Are there any statistically significant differences in the prevalence of the irrational thoughts among students due to gender? To answer the second question, the researchers calculated means and standard deviations, using the t-test for two independent samples to calculate the significance of differences between males and females in the spread of irrational thoughts among students at the University of Najran as shown in table (2).

\begin{tabular}{|c|c|c|c|c|c|c|c|c|c|}
\hline \multicolumn{10}{|c|}{ Group Statistics } \\
\hline & Gender & N. & Mean & $\begin{array}{c}\text { Std. } \\
\text { Deviation }\end{array}$ & $\begin{array}{c}\text { Std. Error } \\
\text { Mean }\end{array}$ & $\begin{array}{c}\text { Mean } \\
\text { Difference }\end{array}$ & T-value & $\begin{array}{l}\text { Degree } \\
\text { of } \\
\text { freedom }\end{array}$ & $\begin{array}{l}\text { Sig. } \\
\text { (2-taile } \\
\text { d) }\end{array}$ \\
\hline Irrational & Male & 141 & 70.9220 & 4.62921 & .38985 & \multirow{2}{*}{5.89567} & \multirow{2}{*}{12.075} & \multirow{2}{*}{291} & \multirow{2}{*}{.000} \\
\hline thoughts & Female & 152 & 65.0263 & 3.70600 & .30060 & & & & \\
\hline
\end{tabular}

Table (2) indicates that the number of males is (141) i.e. $(48.12 \%)$ and females $=(152)$ rated $(51.88 \%)$, the mean of males $=(70.92)$ with a standard deviation (4.63), while the mean of females $=(65.03)$ with a standard deviation (3.71) and mean difference between males and females was (5.89) in favor of females. To calculate the significance of these differences, the researchers used the t-test for two independent samples, where T-value $=(12.075)$ with degree of freedom $=(291)$ and the p-value was $(000)$, and this value is smaller than p-value (0.05) for the study, so the null hypothesis is rejected. Mean difference was (5.89) in favor of females, which means that females more rational than males.

The results showed that irrational thoughts spread much higher among male students than female students. This result is consistent with the results of Mejali, (2011) and Abdel-Ghaffar(2007); and inconsistent with the results of Khaledian; Saghfi; Moradi; \& Khairkhah (2013) and Sachs (2004).

The researchers confirm that the spread of the irrational thoughts among male students is much higher than female students due to the nature of socialization that pays great attention to all family members, especially females, where parents assign females the responsibilities at an early age, and female behavior is monitored more than male one, which makes them more rational than males. In addition, the females reveal their interest in harmony with the expectations of the people around them to be more acceptable in the social environment, in which they are living to have love, attention and care. It is also noticeable that males were given more freedom than males, and this gave the males an opportunity to engage with the peer group and to submit to the conditions of membership, which had a negative impact on increasing irrational thoughts among male students.

Results of the third question: Are there any statistically significant differences in the degree of the spread of irrational thoughts among students due to the type of college (scientific, humanities)? To answer the third question, the researchers calculated means and standard deviations, and conducted t-test for two independent samples to calculate the significance of 
differences between the humanities track and the scientific track in the spread of irrational thoughts among students at the University of Najran as shown in table (3).

\begin{tabular}{|c|c|c|c|c|c|c|c|c|c|}
\hline \multicolumn{10}{|c|}{ Group Statistics } \\
\hline & College & $\mathrm{N}$ & Mean & $\begin{array}{c}\text { Std. } \\
\text { Deviation }\end{array}$ & $\begin{array}{c}\text { Std. Error } \\
\text { Mean }\end{array}$ & $\begin{array}{c}\text { Mean } \\
\text { Difference }\end{array}$ & $\begin{array}{c}\text { T-valu } \\
\text { e }\end{array}$ & D.F & $\begin{array}{c}\text { Sig. } \\
\text { (2-tailed } \\
\text { ) }\end{array}$ \\
\hline \multirow{2}{*}{$\begin{array}{l}\text { Irrational } \\
\text { thoughts }\end{array}$} & $\begin{array}{c}\text { Humanit } \\
\text { ies }\end{array}$ & 156 & 69.3526 & 4.89740 & .39211 & \multirow{2}{*}{3.18468} & \multirow{2}{*}{5.595} & \multirow{2}{*}{291} & \multirow{2}{*}{.000} \\
\hline & $\begin{array}{c}\text { Scientifi } \\
\text { c }\end{array}$ & 137 & 66.1679 & 4.81964 & .41177 & & & & \\
\hline
\end{tabular}

Table (3) shows that the number of humanities students was (156) rated (53.24\%) and the number of students in the scientific track was (137) rated $(46.76 \%)$, the mean of humanities track was (69.35) with a standard deviation (4.89), while the mean of the scientific track was (66.17) with a standard deviation (4.82) and the mean difference between them (3.20) in favor of the scientific track. To calculate the significance of these differences, the researchers conducted the t-test for two independent samples, where T-value was (5.595) with degree of freedom $=(291)$ and the p-value was (000), and this value is smaller than the value (0.05) of the study, so the null hypothesis was rejected that is there are statistically significant differences at the level (0.05) between the track of humanities and the scientific track in favor of the scientific track with mean difference (3.20).

The results showed that the spread of irrational thoughts among the students of humanities track students is higher than its spread among students of scientific track in Najran University. This result is consistent with the results of Abdel-Ghaffar(2007) and Asaleya(2002).

The researchers see that the spread of irrational thoughts among scientific track students is low compared to those of humanities track due to the nature of cognitive structures and the nature of thinking pursued by the students of scientific track, the scientific track students have positive self-concept and self-efficiency that made them more logical and realistic than students of humanities track. The nature and form of the boosters received by the scientific track students from the parents and those around them is far greater than what is received by humanities track students; this of course is reflected positively on their motivation and increased the level of their ambitions and enabled them to be more ambitious, optimistic, motivated and more capable of predicting the future. In addition, the prevailing culture in the community in which the students live has a clear impact on the spread of irrational thoughts among humanities track students, as this track has not received the same cultural importance like the scientific track, which had a negative impact on the manner and style of student life.

The results of the fourth question: Are there any statistically significant differences in the degree of spread of irrational thoughts among students due to the academic level? To answer 
the fourth question, the researchers calculated the means and standard deviations as shown in table (4) and conducted the test of variance (ANOVA) to calculate the significance of differences in the degree of spread of irrational thoughts among the students due to their academic level as indicated in table (5). As well as the researchers utilized Scheffe Test for post-comparisons as illustrated in table (6).

Table (4) indicates that the means of the four levels were $(41.54,69.66,66.39,64.32)$ respectively, and a standard deviation $(5.70,4.48,3.67,3.41)$ respectively. The means indicate face differences, almost regular between the four levels. See Table (4):

Table 4. Means and Standard Deviations

\begin{tabular}{l|c|c|c|c}
\hline \multicolumn{5}{l}{ Irrational thoughts } \\
\hline Level & $\mathrm{N}$ & Mean & Std. Deviation & Std. Error \\
\hline First level & 61 & 71.5410 & 5.70255 & .73014 \\
\hline Second level & 82 & 69.6585 & 4.48652 & .49545 \\
\hline Third level & 77 & 66.3896 & 3.67837 & .41919 \\
\hline Fourth level & 73 & 64.3288 & 3.41180 & .39932 \\
\hline Total & 293 & 67.8635 & 5.10725 & .29837 \\
\hline
\end{tabular}

To check the significance of differences, the researchers used the test of variance (ANOVA) shown in table (5), where the sum of the squares between the groups was (2168.531) with degree of freedom $=(3)$ and mean $(722.844)$; but within the groups, the sum of squares (5448.008), degree of freedom (289) and mean (18.851) and F-value was (38.345) and the Pvalue was (000), and this value is smaller than the P-value (0.05) specific for the study and therefore the null hypothesis was rejected: namely there are statistically significant differences at least between two levels in the degree of the spread of irrational thoughts among Najran University students attributed to the academic level. 
Table 5. ANOVA for significance of differences in the degree of the spread of irrational thoughts among Najran University students due to academic level

\begin{tabular}{l|c|c|c|c|c}
\hline & $\begin{array}{c}\text { Sum of } \\
\text { Squares }\end{array}$ & DF & Mean Square & F & Sig. \\
& 2168.531 & 3 & 722.844 & & \\
\cline { 1 - 3 } Between Groups & 5448.008 & 289 & \multirow{2}{*}{18.851} & \multirow{2}{*}{38.345} & .000 \\
\cline { 1 - 3 } Within Groups & 7616.539 & 292 & & \\
\hline Total & & & & \\
\hline
\end{tabular}

To identify the attitudes of these differences, the researchers utilized (Scheffe) posterior comparisons shown in table (6), the results showed that there were statistically significant differences between the first level and each of the third and the fourth level(5.151 and 7.21) respectively in favor of the first level, as well as there were differences between fourth level and each of the first, second and third level were $(7.21,5.32,2.06)$ respectively in favor of the first, second and third level; and there were differences between the third level and each of the first and second level were (5.15 and 3.27) respectively in favor of the first and second level.

Table 6. Scheffe Test

\begin{tabular}{c|c|c|c|c}
\hline \multicolumn{5}{c}{ Multiple Comparisons - Scheffe } \\
\hline Mean & Level & First level & Second level & Third level \\
\hline 71.54 & $1^{\text {st }}$ level & & & $5.15137^{*}$ \\
\hline 69.66 & $2^{\text {nd }}$ level & & & $3.26893^{*}$ \\
\hline 66.39 & $3^{\text {rd }}$ level & $5.15137^{*}$ & $3.26893^{*}$ & \\
\hline 64.33 & $4^{\text {th }}$ level & $7.21222^{*}$ & $5.32977^{*}$ & $2.06084^{*}$ \\
\hline
\end{tabular}

* The mean difference is significant at the 0.05 level.

This result is consistent with the results of Smith (2008) and Khaledian; Saghfi; Moradi; \& Khairkhah (2013)

The researchers believe that there are a variety of factors and reasons that may be responsible for reducing the irrational thoughts among third and fourth level students, the most important factor is the experience and maturity factor, where those students have the experience that qualifies them to adapt with the university environment, and their awareness of knowledge has become more matured compared with the first and second levels students. The impact of communication skills also has a vital role in reducing irrational thinking of the individual, so 
it is obvious that the students who have passed a great deal of university life are more open and flexible than the students who are in the first levels.

\section{Recommendations}

The present study recommended organizing several workshops to discuss the negative impacts of irrational thoughts and self-defeating thoughts.

Proposals: The researchers of the present study proposed conducting studies that investigate the irrational thoughts and its relation to other variables such as family income and parents' level of education.

Acknowledgments: The researchers would like to extend their gratitude to the Deanship of Scientific Research at Najran University for funding this research project, under the grant number (NU/SHED14/183).

\section{References}

Abdul Ghaffar, Ghada. (2007). Irrational thoughts as predictors of depression disorder among a sample of university students. Journal of Studies, 17(3).

Abu Sha'ar, Abdel-Fattah. (2007). Irrational thoughts of the Palestinian university students and its relationship with some variables, unpublished Master Thesis, Islamic University, Gaza, Palestine.

Al-ezza, Said, \& Ezzat, Hadi. (1999).Theories of counseling and psychotherapy. Amman, Culture House for Publishing and Distribution.

Alrihani, Solomon. (1987). Irrational thoughts irrationality among Jordanians and Americans, cross-cultural study of emotional therapy, Journal of Studies, $14,5$.

Alshenawi, Mohamed. (1994). Counseling and psychotherapy theories. Cairo, Dar Gharib for Publishing and Printing.

Al-Zyoud, Nader. (2008). Theories of counseling and psychotherapy. Amman, Daar alfikr for Publishing and Distribution.

Asaleya, Joseph. (2002). The effectiveness of the emotional and mental-behavioral therapy in reducing anxiety amonga sample of university students. Unpublished PhD Thesis, Al Aqsa University, Gaza.

Corey, G. (2013). Theory and Practice of Counseling and Psychotherapy, Ninth Edition, London, Brooks Cole.

Ellis, A. (2005). The Myth of Self -Esteem, How Rational Emotive Behavior Therapy can change Your Life for Ever, London, Prometheus Books.

Khaledian, M., Saghafi, F., Moradi, S., \& Khairkhah, Z. (2013). Investigating the Relationship of Irrational Beliefs with Anxiety and Their Effect in Two Different Academic Systems in Iran (Under graduate Collage students of PayamNour University and Islamic 
Azad University). International Research Journal of Applied and Basic Sciences, 4(5), 1185-1191.

Maddi, S. (1996). Personality Theories, Broke, Cole Publishing Company, Six Edition, California.

Mejali, Shaye (2011). Irrational thoughts and their relationship to psychological pressure among students of the Faculty of Education in Sa'ada (Yemen), Unpublished MA Thesis, University of Damascus.

Mundada, N. (2013). Locus of Control \& Superstitions. International Journal of Humanities and Social Science Invention, 2(6,1), 11-14.

Murray, H. (1999). Relationship between specific irrational beliefs and hostility anxiety and depression in behavior ally disordered adolescents. Dis. Int, 43(2).

Sachs, J (2004). Superstition and Self-Efficacy in Chinese Postgraduate Students. Psychological Reports, 95(2), 485-486. http://dx.doi.org/10.2466/pr0.95.2.485-486

Smith, A. (2008). Stress and Irrational Beliefs in College Students. AnsiedadEstrés, 14(2-3), 211-220

Stanciu, A. (2014).The Connection between Gender, Academic Performance, Irrational Beliefs, Depression and Anxiety among Teenagers and Young Adults Romania, Journal of Cognitive Behavioral Therapy and Hypnosis, 1(2), 1-13. 